\title{
UTILIZAÇÃO DE DETECÇÃO POR ESPALHAMENTO DE LUZ EVAPORATIVO PARA A ANÁLISE DE PRODUTOS NATURAIS
}

\author{
Raquel P. Morais Urano, Fabiana T. Rodrigues e Roberto G. S. Berlinck* \\ Instituto de Química de São Carlos, Universidade de São Paulo, CP 780, 13560-970 São Carlos - SP, Brasil
}

Recebido em 13/9/11; aceito em 14/12/11; publicado na web em 23/3/12

\begin{abstract}
EVAPORATIVE LIGHT-SCATTERING DETECTOR FOR ANALYSIS OF NATURAL PRODUCTS. The interest in the use of evaporative light scattering detector (ELSD) for the analysis of different classes of natural products has grown over the years. This is because this detector has become an excellent alternative compared to other types of detectors, such as the refractive index detector and the ultraviolet (UV) detector. This review describes the basic principles of ELSD functioning and discusses the advantages and disadvantages in using an ELSD for the analysis of organic compounds. Additionaly, an overview, covering the last 23 years, of ELSD applications in natural products analysis (saponins, terpenes, carbohydrates, glycosides, alkaloids, steroids, flavonoids, peptides, polyketides, coumarins and iridoids) is presented and discussed.
\end{abstract}

Keywords: ELSD; natural products; HPLC analysis.

\section{INTRODUÇÃO}

O detector por espalhamento de luz evaporativo (evaporative light scattering detector - ELSD) foi inventado, em 1966, por cientistas da Union Carbide australiana ${ }^{1}$ e tornou-se comercialmente disponível a partir dos anos 80, após uma série de estudos teóricos e refinamento da técnica. ${ }^{2}$ Foram desenvolvidas modificações instrumentais com o objetivo de tornar o ELSD compatível com colunas capilares e microbore. A principal alteração foi na redução do diâmetro do capilar do nebulizador com o intuito de aumentar a velocidade linear da fase móvel e a eficiência da produção do aerossol. Essa mesma modificação também é apropriada no caso da conexão de ELSD com cromatógrafo líquido de alto desempenho acoplado a um espectrômetro de massas (HPLCMS), ou a um cromatógrafo líquido de alto desempenho acoplado a um espectrômetro de ressonância magnética nuclear (HPLC-NMR). Um ELSD também pode ser modificado para fornecer detecção simultânea de até quatro sistemas independentes de HPLC. ${ }^{1}$

Existem diversos ELSDs comercialmente disponíveis. A maioria deles possui uma simples câmara de nebulização para eliminação das partículas maiores. Foi desenvolvido um ELSD de modo duplo, com a capacidade de operar utilizando um adaptador removível. ${ }^{1}$ Hoje em dia o ELSD é um dos principais detectores utilizados com aparelhos de HPLC. Também é compatível com um cromatógrafo em contracorrente em alta velocidade (HSCCC) e um cromatógrafo com fluido supercrítico (SFC). ${ }^{1}$

O interesse pela utilização de detectores por espalhamento de luz vem crescendo ao longo dos anos (Figura 1) e isso se deve a algumas características especiais da técnica, como a compatibilidade com gradientes de eluição (o que representa uma vantagem em relação a detectores de índice de refração), o baixo custo, a facilidade de operação e a insensibilidade da detecção a variações na temperatura. ${ }^{1}$ O ELSD é considerado um detector pseudouniversal, uma vez que analitos com volatilidade maior do que a fase móvel não poderão ser detectados. ${ }^{1}$ Além disso, este detector mostrou ser uma excelente alternativa frente a outros tipos de detectores, incluindo o detector de ultravioleta (UV), uma vez que este último detecta apenas substâncias com grupos cromóforos, requisito desnecessário na detecção por um ELSD. ${ }^{2}$

\footnotetext{
*e-mail: rgsberlinck@iqsc.usp.br
}

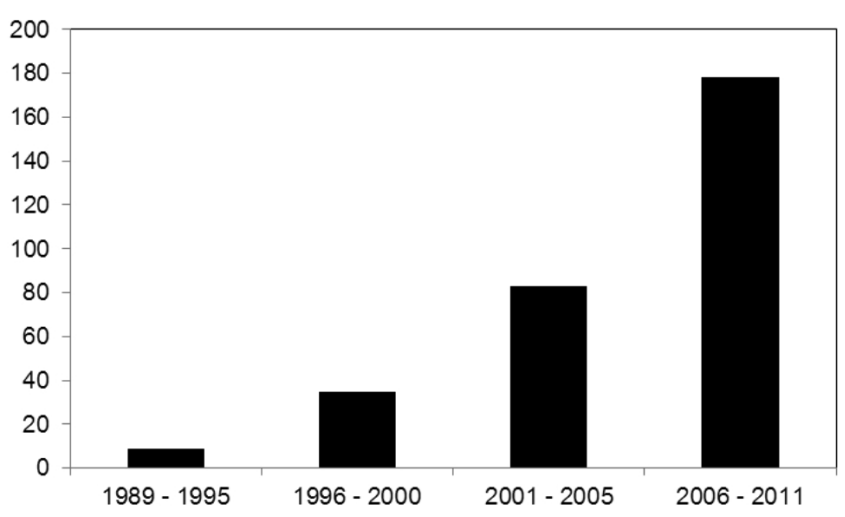

Figura 1. Número de artigos publicados de 1989 a maio de 2011, nos quais é utilizado ELSD para análise de produtos naturais. Fonte: ISIknowledge

\section{PRINCÍPIOS DA TÉCNICA}

O detector por espalhamento de luz evaporativo (ELSD) pode ser usado para a análise de todo soluto que seja menos volátil que a sua fase móvel. A maioria dos outros tipos de detectores se restringe à detecção de substâncias com propriedades físico-químicas definidas, ao uso de um número limitado de solventes (por exemplo, sem absorção no UV entre 200 e 400 nm), ou ao uso de eluição isocrática. O ELSD pode ser utilizado com eluição isocrática, com gradientes complexos de eluição e para a detecção de qualquer tipo de substância menos volátil do que o eluente. ${ }^{3}$

O princípio de operação de um ELSD envolve 3 etapas (Figura 2): nebulização, evaporação e detecção. Primeiramente, o eluente que sai da coluna carregando a amostra é vaporizado com um dispositivo automático de entrada de um gás nebulizador (nebulização). A seguir, gotas do eluente contendo o analito são carregadas por um tubo onde o solvente é evaporado e é formado um aerossol. Finalmente, o gás que transporta as partículas da amostra passa através de uma pilha ótica e a quantidade de luz dispersada é medida (detecção). A resposta é diretamente relacionada com a concentração de material eluído. ${ }^{2,4}$

A resposta do detector depende do tamanho e da forma dos agregados dessolvatados de partículas que permanecem após o estágio da evaporação. O ELSD não fornece informações a respeito da massa 

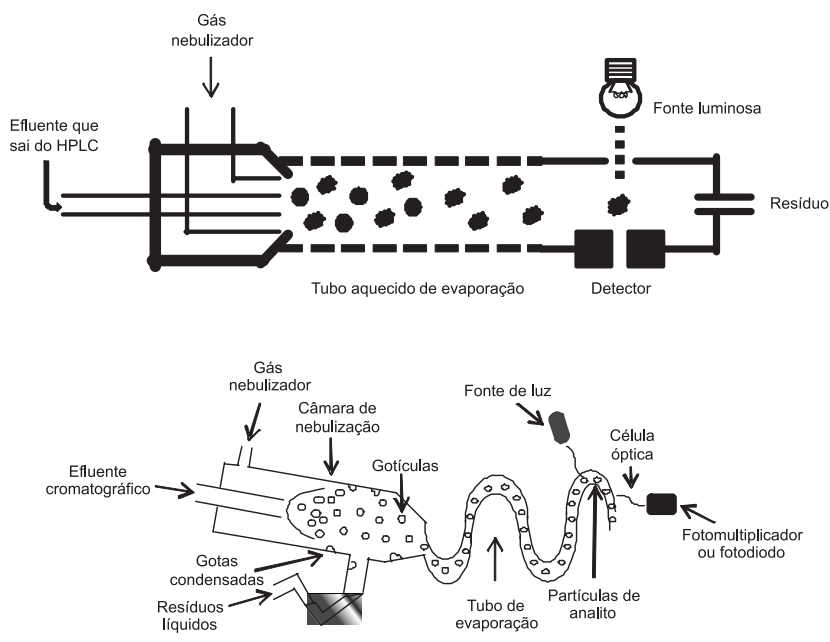

Figura 2. Esquema de um detector por espalhamento de luz evaporativo. Adaptado das refs. 1 e 2

molecular do analito, ao contrário da detecção por espalhamento de luz não evaporativa, ${ }^{5}$ que é utilizada na análise da massa molar de polímeros. A quantidade de luz dispersada é proporcional somente à quantidade de amostra na pilha. Portanto, a detecção não requer que os analitos apresentem grupos funcionais específicos ou cromóforos. ${ }^{2}$

A nebulização é a primeira etapa do mecanismo de detecção por ELSD e é a mais importante para se ter sucesso quando do uso deste detector. O eluente carregando a amostra sai da coluna cromatográfica e entra em um nebulizador. O gás nebulizador transforma o eluente em um aerossol, onde o gás nebulizador pode ser nitrogênio ou hélio, os mais utilizados. ${ }^{1,2}$

A segunda etapa inicia quando as gotículas de eluente e de analito são arrastadas pelo fluxo de gás para um tubo aquecido (drift tube), ocorrendo a evaporação da fase móvel, permanecendo somente as partículas do analito no gás carregador. Nesta etapa, a escolha de temperatura adequada de evaporação é essencial. A temperatura de evaporação deve ser estabelecida de acordo com a volatilidade do analito e da fase móvel. A temperatura de evaporação é normalmente fixada entre 30 e $100{ }^{\circ} \mathrm{C} .{ }^{1,2} \mathrm{Em}$ cromatografia de fase reversa as condições iniciais do gradiente são fatores limitantes e a temperatura de evaporação tem que ser definida de acordo com o solvente escolhido. ${ }^{2}$ Se for utilizada uma temperatura muito baixa, alguns solventes podem entrar no detector na forma líquida resultando em ruído ou sinais pontiagudos na linha de base, tornando impossível uma análise mais precisa. ${ }^{1,2}$ No caso de altas temperaturas pode ocorrer uma diminuição na sensibilidade do ELSD se forem analisados compostos parcialmente voláteis. O tamanho das partículas que entram no detector após a evaporação depende do diâmetro das gotículas, bem como da concentração e da densidade do analito. ${ }^{2}$

O detector que mede a quantidade de luz espalhada é composto por uma fonte de luz e um fotomultiplicador, ou fotodiodo, fornecendo um sinal de resposta. O uso de luz monocromática não parece ser significativamente vantajoso, porém a utilização de radiação luminosa de comprimentos de onda mais curtos geralmente melhora a sensibilidade dos detectores. ${ }^{1,2}$ A quantidade de luz dispersada é controlada pelo diâmetro da partícula, pelo comprimento de onda da luz e pelo ângulo da luz espalhada. ${ }^{1}$

A resposta do detector está relacionada com a área do pico $(A)$ observada e a quantidade de analito $(C)$ na coluna obedecendo a equação $A=a x C^{b}$, onde " $a$ " e " $b$ " são constantes numéricas. A distribuição do tamanho das partículas formadas no aerossol é variável e depende da natureza do solvente utilizado, o que influencia a resposta da detecção. Além disso, a quantidade de luz espalhada depende fortemente da absortividade molar do soluto. ${ }^{3}$ Para este detector não existem requisitos especiais para o comprimento de onda da fonte luminosa; em alguns instrumentos comerciais, é utilizada simplesmente uma lâmpada de retroprojetor. Como detector, o ELSD pode ser considerado universal em sua aplicabilidade, na medida em que responderá a qualquer soluto que não evapore antes de passar pelo feixe de luz. ${ }^{4}$

Os parâmetros que mais influenciam na resposta do detector são a temperatura do drift tube e o fluxo do gás nebulizador, tornando-se necessária a otimização destas condições e a calibração do instrumento para se obter uma melhor resposta nas análises. Uma vez que as condições forem otimizadas para uma separação em particular, estes devem ser mantidos constantes enquanto a calibragem é realizada utilizando-se amostras padrões relacionadas àquelas que serão analisadas. ${ }^{3}$

Um ELSD pode ser usado com a maioria dos solventes para se otimizar a seletividade na separação, além de sua utilização ser altamente flexível, já que pode ser alterado de um modo de análise para outro (normal ou reverso). ${ }^{3}$ Uma vez que o instrumento foi aquecido e está em execução, o desvio que ocorre na linha de base é muito pequeno durante a análise, mesmo com mudanças abruptas na composição do solvente. A maioria dos solventes orgânicos como acetona e clorofórmio, por exemplo, pode ser usado com este detector, além de poderem ser utilizados com mais de $20 \%$ de água em um gradiente e, também, conter pequenas espécies iônicas. O limite de detecção depende, de certa forma, da natureza da fase móvel, da natureza da amostra e da especificidade do instrumento. ${ }^{4}$

\section{VANTAGENS}

A principal vantagem de um detector por espalhamento de luz evaporativo (ELSD) é a sua habilidade em detectar quase todas as classes de compostos, independentemente de suas propriedades físicas ou químicas, o que torna esta técnica versátil e robusta (Figura 3). Também pode ser utilizada uma ampla variedade de solventes, tanto para cromatografia de fase normal quanto para cromatografia de fase reversa. ${ }^{2}$

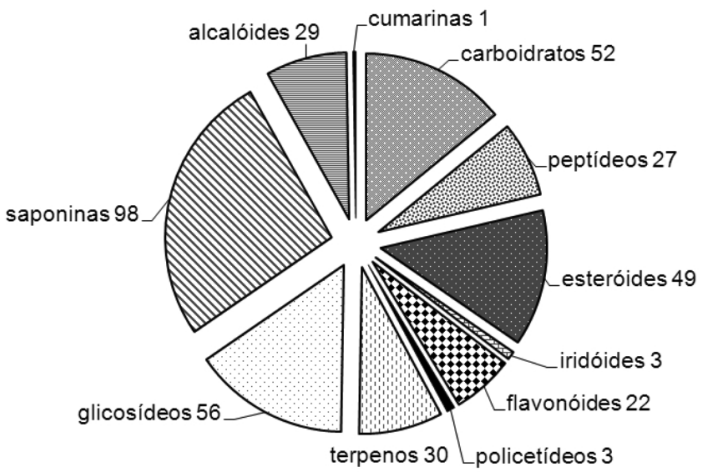

Figura 3. Número de artigos por classe de produtos naturais analisados por ELSD. Fonte: ISIknowledge, pesquisa realizada no período de abril-maio de 2011

O ELSD não é afetado por mudanças na temperatura ambiente, é de fácil operação e quase não necessita de manutenção. ${ }^{2,4}$ Podem ser feitos ajustes rápidos, que são muitas vezes necessários durante o desenvolvimento de um método. A sensibilidade dos instrumentos mais recentes é equivalente à dos detectores de índice de refração e é ainda melhor do que a dos detectores de ionização em chama, ou dos detectores de UV operando em baixos comprimentos de onda. ${ }^{2,6}$ Cobb e colaboradores ${ }^{6}$ realizaram estudos comparativos entre o 
uso do ELSD e do detector de UV para a análise de aminoácidos. Os resultados mostraram que, utilizando-se gradiente de eluição, o ELSD é mais sensível que o detector de UV. Isso ocorre porque o detector de UV, ao contrário do ELSD, é sensível a mudanças na composição da fase móvel, resultando em uma linha de base muito instável, o que dificulta a identificação e integração dos picos no cromatograma. Assim, o ELSD pôde oferecer melhores limites de detecção mesmo para analitos que possuíam cromóforos com forte absorção no UV.

A linearidade do ELSD está relacionada com a homogeneidade das gotas do analito formadas na câmara de nebulização. A resposta do ELSD é dependente tanto da composição da fase móvel quanto da taxa de fluxo. ${ }^{6} \mathrm{O}$ uso de uma baixa taxa de fluxo (para cromatografia com microcolunas e colunas capilares) melhora a distribuição do tamanho das gotas, tornando sua distribuição mais homogênea. ${ }^{6} \mathrm{Cobb}$ e colaboradores ${ }^{6}$ demonstraram que ELSD acoplado a um HPLC com o uso de microcoluna apresenta uma boa linearidade para a análise de aminoácidos na faixa de 0,5 a $500 \mathrm{ng}$, comparando-se curvas de calibração de 4 diferentes aminoácidos. Foi possível observar que a linearidade foi mantida para 3 dos 4 aminoácidos ao final da curva de calibração na faixa de 0 a $50 \mathrm{ng}$.

Chopra e colaboradores ${ }^{7}$ realizaram um estudo comparativo entre diferentes modelos de ELSD e um detector eletroquímico pulsado (PED), que também é utilizado para a detecção de substâncias sem grupos cromóforos, acoplados a um HPLC. Foi realizada a análise de tobramicina, um aminoglicosídeo sem grupos cromóforos, onde o ELSD mostrou linearidade similar ao PED, porém foi necessária uma transformação $\log -\log$ dos dados com base na relação $A=a$ $x C^{b}$ para se obter essa resposta. Quanto à sensibilidade, o ELSD foi menos sensível do que o PED devido a impurezas presentes na amostra, o que dificultou a análise. Para se ter uma boa resposta seria necessária uma limpeza prévia da amostra. Neste estudo o modelo ELSD 3300 mostrou uma sensibilidade bem mais baixa do que o modelo ELSD 2000, apresentando um cromatograma com muitos ruídos na linha de base e muitos picos que podem ser resultado da nebulização incompleta da fase móvel.

Apesar de ser um detector destrutivo devido à perda de amostra, é possível inserir um divisor de fluxo entre o final da coluna e a entrada do detector, no qual grande parte da amostra poderá ser desviada e recuperada. Desta forma, o detector torna-se uma excelente ferramenta de pesquisa, uma vez que a amostra pode ser facilmente coletada ou redirecionada para outros detectores, como para um espectrômetro de massas, por exemplo. ${ }^{4}$

\section{DESVANTAGENS}

Alguns dos fatores limitantes para o uso do ELSD se referem a sua restrição quanto à volatilidade da fase móvel e do analito. A fase móvel deve ser completamente volátil ou, então, resíduos irão se depositar na câmara de aquecimento e bloquearão a célula óptica. ${ }^{2}$ Reagentes com pareamento de íons, modificadores não voláteis, ácidos, bases e tampões não podem ser usados em ELSD. Alguns modificadores voláteis são aceitáveis como os ácidos acético, fórmico e trifluoroacético. ${ }^{1}$

Compostos que estejam em concentrações muito baixas, a um nível de ng/mL, poderão não ser detectados (o limite de quantificação deve ser acima de $0,1 \mu \mathrm{g} / \mathrm{mL}$ ). Nestes casos é necessária uma etapa de pré-concentração para se enriquecer a amostra a ser analisada ${ }^{1} \mathrm{e}$ uma limpeza prévia da amostra para a retirada de interferentes. O detector por espalhamento de luz é destrutivo e, portanto, deve ser o último em linha se for usado em série com outros detectores. ${ }^{1}$ É necessário um compressor de ar que seja capaz de fornecer $5 \mathrm{~L} / \mathrm{min}$ de ar comprimido filtrado, ou seja, um cilindro padrão de ar ou nitrogênio é esvaziado entre 4 e $8 \mathrm{~h}$. O fluxo de ar que contém o solvente que foi evaporado deve ser conduzido para fora do laboratório ou para um exaustor. ${ }^{4}$

\section{APLICAÇÕES NA ANÁLISE DE PRODUTOS NATURAIS}

Os detectores por espalhamento de luz evaporativo estão sendo amplamente utilizados para a análise de amostras de diferentes classes de produtos naturais. Para exemplificar, foi realizado um levantamento de dados da literatura dos últimos 23 anos (1989 - 2011; publicações apenas em inglês), utilizando-se como base de dados ISI Web of Knowledge e como palavras-chave: evaporative light scattering, natural products, saponins, flavonoids, terpenes, carbohydrates, glycosides, alkaloids, peptides, steroides, polyketides, iridoids e coumarins.

\section{Saponinas}

As saponinas foram objeto de estudo de vários grupos que realizaram a sua identificação, quantificação e separação por ELSD acoplado a um HPLC com o uso de cromatografia de fase reversa (RP) como, por exemplo, He e colaboradores, ${ }^{8}$ que realizaram a determinação de glicosídeos triterpênicos presentes em espécies de Cimicifuga, e Kwon e colaboradores, ${ }^{9}$ que utilizaram HPLC-ELSD na determinação de 19 ginsenosídeos presentes na raiz da planta Panax ginseng. $\mathrm{O}$ ginseng é uma das plantas mais estudadas do mundo e possui saponinas com atividades biológicas como hipoglicemiante, anticancerígena e estimulante do sistema nervoso central (SNC), bem como propriedades anti-stress. A detecção de saponinas é difícil e apresenta ruídos na linha de base devido a sua fraca absorção no UV. ${ }^{10}$ No trabalho realizado por Kwon e colaboradores ${ }^{9}$ foi utilizada uma coluna $\mathrm{C}_{18}$ e um gradiente de acetonitrila em água com $5 \%$ de ácido acético, temperatura do drift tube de $40{ }^{\circ} \mathrm{C}$ e pressão do gás nebulizador de 1,8 bar. A metodologia empregada foi precisa, apresentando um desvio padrão relativo (DPR) em uma faixa de 0,04-5,8\% para as análises intradia e 0,65-8,5\% para as análises interdia. Em 2002, Li e Fitzloff ${ }^{10}$ desenvolveram um método para identificação de ginsenosídeos presentes nas raízes de ginseng asiático (Panax ginseng) e ginseng norte americano ( $P$. quinquefolius) utilizando tanto UV quanto ELSD. O gradiente usado foi de acetonitrila em água em uma coluna $\mathrm{C}_{18}$. Para o ELSD, a pressão do gás nebulizador foi de 3,4 bar e a temperatura do drift tube de $35^{\circ} \mathrm{C}$. O ELSD mostrou uma boa sensibilidade e um limite de detecção mais baixo que o UV, uma vez que foi possível distinguir o ginseng asiático do ginseng norte americano, com baixas concentrações de amostra $(32-50 \mathrm{ng} / \mathrm{mL})$. Para o detector de UV foram necessários $1060 \mathrm{ng} / \mathrm{mL}$ de amostra para a observação do pseudoginsenosídeo $\mathrm{F}_{11}(\mathbf{1})$, com uma absorção muito fraca, diferentemente do ELSD no qual o pseudoginsenosídeo $\mathrm{F}_{11}$ foi observado com uma concentração mínima de $32 \mathrm{ng} / \mathrm{mL}$. Os ginsenosídeos $\mathrm{Rg}_{1}$, Re, $\mathrm{Rf}(\mathbf{2}), \mathrm{Rb}_{1}, \mathrm{Rc}, \mathrm{Rb}_{2}$ e Rd foram observados no ELSD com uma concentração mínima de 50 ng/mL (Figura 4).

Rupasinghe e colaboradore ${ }^{11}$ realizaram a análise de sapogenol de soja A (3) e B (4), Figura 5, encontrados em soja (Glycine max L. Merr.), por HPLC-ELSD com uma fase móvel composta de acetonitrila, propanol, água e $0,1 \%$ de ácido acético, uma coluna $\mathrm{C}_{18}$, temperatura do drift tube de $70{ }^{\circ} \mathrm{C}$ e um fluxo de nitrogênio em $2 \mathrm{~mL} / \mathrm{min}$. O ELSD apresentou alta sensibilidade, com limites de detecção para o sapogenol de soja A e B de 0,06 e $0,08 \mathrm{mg} / \mathrm{g}$, respectivamente. Cao e colaboradores ${ }^{12}$ isolaram e identificaram ginsenosídeos utilizando ELSD acoplado a um cromatógrafo em contracorrente em alta velocidade (HSCCC). Foi empregada uma fase móvel composta por uma mistura de acetato de etila, butanol e água. O efluente usado em HSCCC foi dividido e uma parte do solvente foi usada para monitorar a separação por ELSD, resultando na purificação de 5 saponinas. 


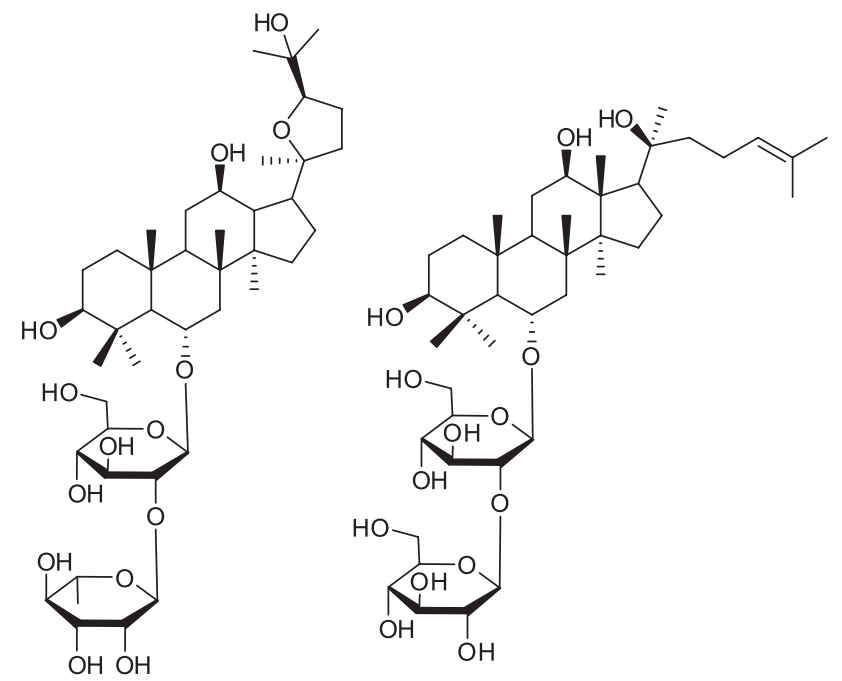

pseudoginsenosídeo F11 (1)

$\operatorname{Rf}(2)$

Figura 4. Estrutura do pseudoginsenosídeo $F 11$ (1) e do ginsenosídeo $R f(2)^{10}$

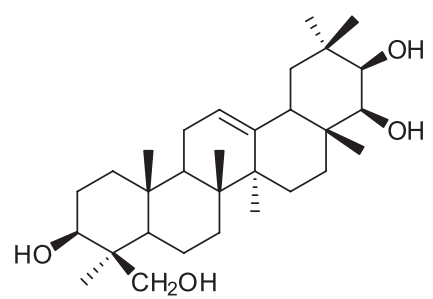

sapogenol de soja $\mathrm{A}$

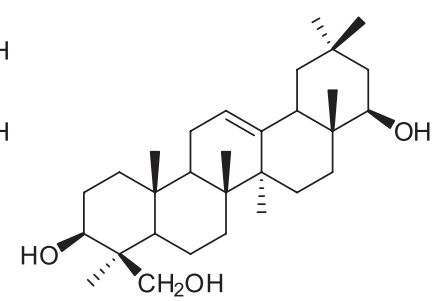

sapogenol de soja B
(4)
Figura 5. Estruturas do sapogenol de soja $A(3)$ e do sapogenol de soja $B(4)^{11}$

Wang e colaboradores ${ }^{13}$ estudaram a qualidade da planta medicinal Polygala japonica, utilizada como agente anti-inflamatório, antibacteriano, antidepressivo e expectorante. Os autores estabeleceram um método utilizando HPLC-ELSD para avaliar a qualidade desta planta. Para isso foi empregada uma coluna $\mathrm{C}_{18}$ com um gradiente de eluição de acetonitrila e metanol com ácido trifluoroacético (TFA) a $0,05 \%$. O método foi reprodutível, apresentando um desvio padrão relativo $(\mathrm{DPR}) \leq 5 \%$ para análises interdia e intradia. O grupo utilizou o mesmo método, em 2010, para avaliação do controle de qualidade de P. japonica ${ }^{14}$ Desta vez, compararam o uso do detector de UV (arranjo de diodos) com o ELSD acoplados em série (HPLC-DADELSD). Foram observados poucos sinais característicos de saponinas nos cromatogramas de $\mathrm{DAD}$, porém foi observada uma maior quantidade de sinais nos cromatogramas de ELSD, identificados como triterpenos glicosilados (saponinas).

Bhandari e colaboradore ${ }^{15}$ realizaram a quantificação de bacosídeos e apigenina presentes em Bacopa monnieri por HPLC-ELSD (Figura 6), utilizando coluna $\mathrm{C}_{18}$, fase móvel de acetonitrila e água e ELSD operando com temperatura do drift tube em $95^{\circ} \mathrm{C}$ e fluxo de gás nebulizador de 2,0 L/min. O método foi reprodutível, preciso, simples e rápido para a quantificação destes compostos. O limite de detecção foi na faixa de 0,54 a $6,06 \mu \mathrm{g} / \mathrm{mL}$ e o limite de quantificação, na faixa de 1,61 a 18,78 $\mu \mathrm{g} / \mathrm{mL}$. Man e colaboradores ${ }^{16}$ desenvolveram um método combinando as técnicas de HPLC-ELSD e HPLC-MS/ MS para a identificação e quantificação de saponinas esteroidais presentes em plantas dos gêneros Paris e Trillium. Utilizaram pela primeira vez estas duas técnicas para avaliar o controle de qualidade das saponinas que tiveram forte efeito antitumoral. Foi empregada uma coluna $\mathrm{C}_{18}$, fase móvel de água e acetonitrila, temperatura do drift tube de $100{ }^{\circ} \mathrm{C}$ e um fluxo de gás nebulizador de $2,7 \mathrm{~L} / \mathrm{min}$. O método de HPLC-ELSD foi validado, apresentando um limite mínimo de detecção de $118,8 \mathrm{ng} / \mathrm{mL}$, exato e preciso para a análise dos extratos brutos. Além disso, o procedimento analítico desenvolvido foi rápido e confiável para o controle de qualidade de Paris e Trillium. Todos os estudos realizados para a análise de saponinas mostraram que o ELSD é muito simples de ser usado e apresenta um bom limite de detecção, alta sensibilidade e resolução para a caracterização e quantificação destas substâncias.

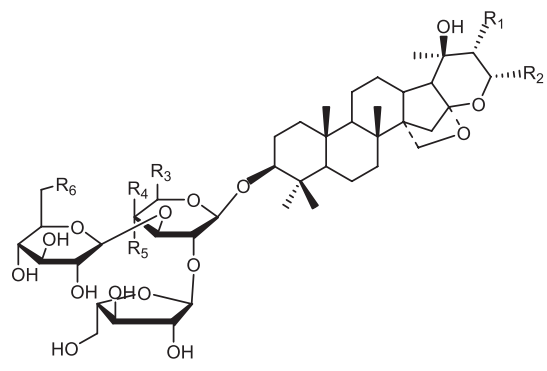

$$
\begin{aligned}
& \begin{array}{lll}
\mathrm{R}_{1} & \mathrm{R}_{2} & \mathrm{R}_{3}
\end{array} \\
& \text { (5) } \mathrm{CH}=\mathrm{C}\left(\mathrm{CH}_{3}\right)_{2} \quad \mathrm{H} \quad \mathrm{H} \\
& \text { (6) } \mathrm{H} \quad \mathrm{CH}=\mathrm{C}\left(\mathrm{CH}_{3}\right)_{2} \mathrm{CH}_{2} \mathrm{OH} \\
& \text { (7) } \mathrm{CH}=\mathrm{C}\left(\mathrm{CH}_{3}\right)_{2} \quad \mathrm{H} \quad \mathrm{CH}_{2} \mathrm{OH} \\
& \text { (8) } \mathrm{H} \quad \mathrm{CH}=\mathrm{C}\left(\mathrm{CH}_{3}\right)_{2} \quad \mathrm{H} \\
& \text { (9) } \mathrm{CH}=\mathrm{C}\left(\mathrm{CH}_{3}\right)_{2} \mathrm{H} \quad \mathrm{H}
\end{aligned}
$$

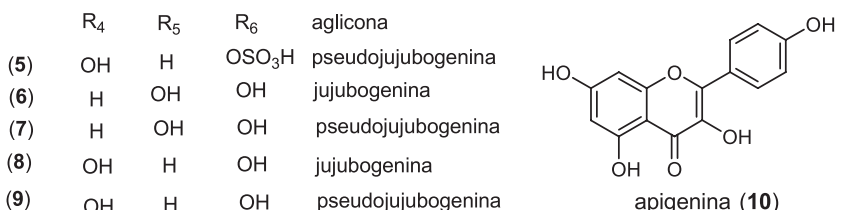

Figura 6. Estruturas dos bacosídeos (5-9) e da apigenina (10) $)^{15}$

\section{Terpenos}

Os terpenos também foram amplamente analisados por HPLCELSD. ${ }^{17-24}$ Avula e colaboradores ${ }^{17}$ descreveram o primeiro método analítico para determinação de 4 glicosídeos (Figura 7) presentes em Sutherlandia frutescens (L.) utilizando HPLC-DAD-ELSD em cromatografia de fase reversa. Foi empregada uma coluna $\mathrm{C}_{18}$, gradiente

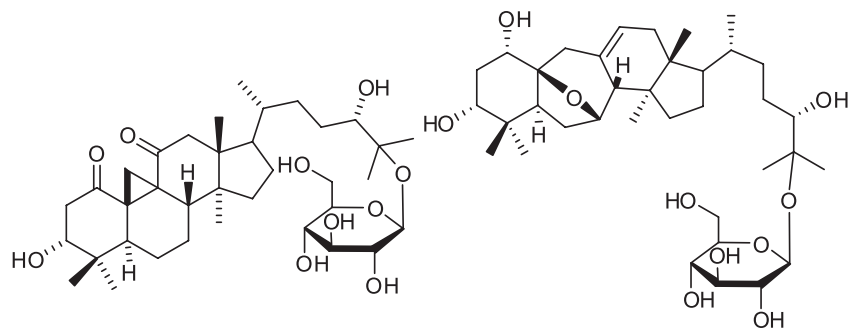
suterlandiosídeo A (11) suterlandiosídeo B (12)

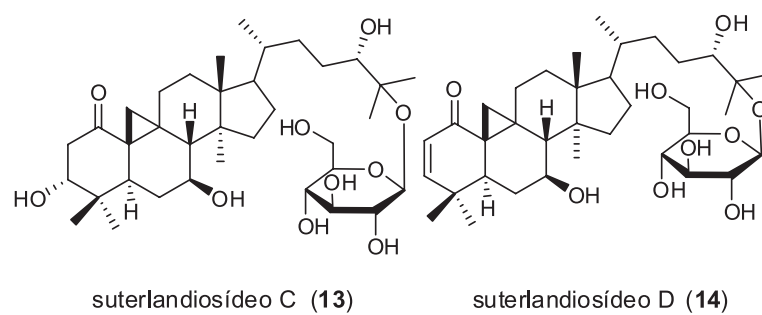

Figura 7. Estruturas dos triterpenos (11-14) ${ }^{17}$ 
de acetonitrila em água e temperatura do drift tube de $43^{\circ} \mathrm{C}$. Com o detector de ELSD foram detectados os glicosídeos que apresentam baixa absorção no UV. O método foi validado em termos de precisão, exatidão e linearidade. O limite de detecção foi na faixa de 0,1 a $7,5 \mu \mathrm{g} / \mathrm{mL}$ e o limite de quantificação, na faixa de 0,5 a $25 \mu \mathrm{g} / \mathrm{mL}$ para todos os compostos.

Kong e colaboradore ${ }^{18}$ realizaram estudos de identificação de terpenos (Figura 8) em Cimicifuga foetida, uma planta medicinal chinesa utilizada como agente antimicrobiano, tranquilizante e hipotensor. Realizaram uma análise quantitativa comparando os métodos de detecção de UV com ELSD nas mesmas condições cromatográficas com coluna $\mathrm{C}_{18}$, um gradiente de eluição de metanol em água, temperatura do drift tube de $119^{\circ} \mathrm{C}$ e um fluxo de gás nebulizador de 2,3 L/min. Os compostos terpênicos acteína (15), 27-deoxiacteína (16) e cimicifugosídeo (17) tiveram uma absorção no UV abaixo de $200 \mathrm{~nm}$, tornando a sua sensibilidade muito baixa. Porém, no ELSD estes compostos puderam ser facilmente detectados. Os limites de detecção do ELSD para acteína, 27-deoxiacteína e cimicifugosídeo foram de 40, 33 e $33 \mathrm{ng} / \mathrm{mL}$, respectivamente, enquanto que para o UV foram de 660, 880 e $427 \mathrm{ng} / \mathrm{mL}$.

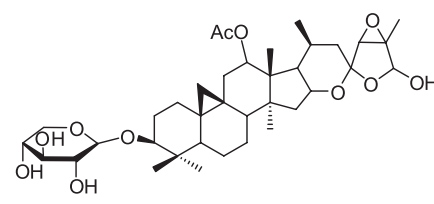

acteína (15)

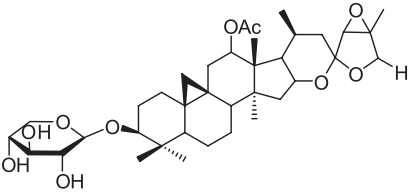

27-deoxiacteína (16)

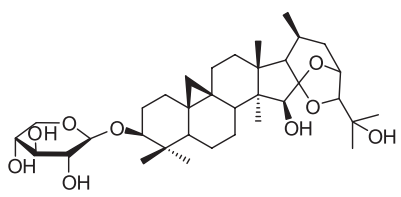

cimicifugosídeo (17)
Figura 8. Estruturas da acteína (15), 27-deoxiacteína (16) e cimicifugosídeo $(17)^{18}$

Christen e Veuthey ${ }^{19}$ desenvolveram um método para análise de artemisinina (18) e seus derivados de Artemisia annua (Figura 9). O método fez uso de ELSD com cromatografia com fluido supercrítico (SFC). O método foi comparado com SFC acoplado a um detector de ionização de chama (FID). Ambos apresentaram resultados semelhantes. Contudo, o SFC-ELSD foi mais rápido, permitindo a separação dos compostos em apenas $8 \mathrm{~min}$. Também foi desenvolvido um método por HPLC-ELSD para análise de artemisinina e ácido artemisínico (19), o qual permitiu a separação das substâncias em menos de 9 min. Este método foi validado para a determinação quantitativa de compostos presentes em Artemisia annua. Lapkin e colaboradore ${ }^{20}$ desenvolveram e validaram um método de quantificação de artemisinina comparando o método de HPLC-UV com HPLC-ELSD, utilizando-se de duas fases móveis com modo de eluição isocrático e gradiente. A fase móvel (1) era composta por acetonitrila/metanol/água e a (2) por acetonitrila/água. O método desenvolvido por HPLC-ELSD apresentou melhor repetibilidade quando usado no modo isocrático e teve um melhor desempenho no caso da quantificação de artemisinina presente no extrato bruto, devido à sua identificação imediata no cromatograma da amostra. Já o método por HPLC-UV no modo gradiente foi mais preciso do que o HPLC-ELSD no modo isocrático para a análise da pureza de artemisinina. De maneira geral, HPLC-ELSD mostrou ser mais robusto tanto para a quantificação de artemisinina em extratos brutos quanto para a otimização de protocolos de extração e purificação. O método de ELSD apresentou maior sensibilidade e estabilidade frente ao UV, tornando seu desempenho eficaz e útil para a análise de compostos terpênicos não voláteis com baixa absorção no UV presentes em plantas medicinais chinesas.
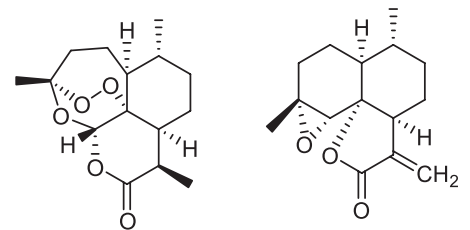

artemisina (18) ácido artemisínico (19)

Figura 9. Estrutura da artemisina (18) e do ácido artemísico (19) ${ }^{19}$

Devkota e colaboradore ${ }^{21}$ realizaram a análise qualitativa e quantitativa de triterpenos bioativos presentes na planta medicinal Centella asiatica (L.) por HPLC-DAD-ELSD. O método foi útil para fornecer informações a respeito das maiores quantidades de triterpenos e fenóis presentes em plantas recorrentes em determinados distritos do Nepal. Van Beek, ${ }^{22}$ Dubber e Kanfer ${ }^{23}$ e Kaur e colaboradores ${ }^{24}$ utilizaram o método para a determinação de trilactonas terpênicas (Figura 10) presentes em amostras de Ginkgo biloba. Esta planta é utilizada como medicamento fitoterápico contra insuficiência renal, depressão, diabetes, doença de Alzheimer, impotência, entre outras aplicações medicinais. Sua atividade está relacionada com flavonoides e lactonas terpênicas, os ginkgolídeos (estruturas de 20 a 24), que são encontrados exclusivamente em Ginkgo biloba. ${ }^{23} \mathrm{O}$ método para a determinação quantitativa destes ginkgolídeos (Figura 10) foi desenvolvido utilizando-se coluna $\mathrm{C}_{18}$, fase móvel de metanol e água, e para o ELSD temperatura do drift tube de $117,5^{\circ} \mathrm{C}$ e um fluxo de gás nebulizador de 1,5 L/min. O método foi validado, apresentando boa reprodutibilidade, exatidão e linearidade com um limite de detecção e de quantificação na faixa de 30 a 60 ng/mL. O uso do ELSD ofereceu vantagens em relação ao detector de UV em termos de sensibilidade e seletividade, além de ser relativamente barato e fácil de ser operado em comparação ao espectrômetro de massas (MS) e com o cromatógrafo a gás (GC).

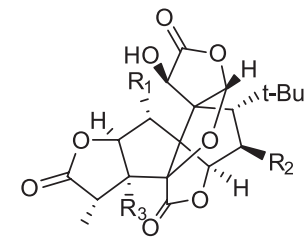

(20) ginkgolídeo $A(G A)$

(21) ginkgolídeo $B(G B)$

(22) ginkgolídeo $C$ (GC)

(23) ginkgolídeo D (GD)

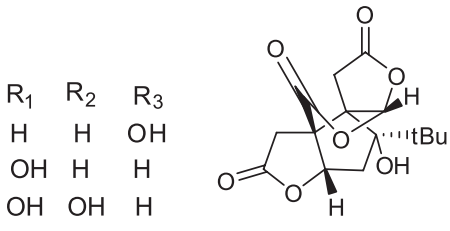

Figura 10. Estruturas das trilactonas terpênicas (20-24) ${ }^{24}$

\section{Carboidratos}

Os carboidratos são geralmente difíceis de serem detectados por métodos convencionais de HPLC associados ao detector de UV por não apresentarem grupos cromóforos. Assim, a técnica de ELSD associada ao HPLC tornou-se uma ferramenta útil para a determinação desta classe de produtos naturais. Diversos estudos foram publicados para a análise de carboidratos por HPLC-ELSD. ${ }^{25-32}$ Wang e colaboradore ${ }^{26}$ realizaram a determinação de manitol, glicose e trealose produzidos pelo fungo Cordyceps sinensis. O método foi validado para precisão, repetibilidade e exatidão, onde, para o ELSD a temperatura do drift tube foi de $94{ }^{\circ} \mathrm{C}$ e o fluxo do gás nebulizador foi de 2,0 
$\mathrm{L} / \mathrm{min}$. Yang e $\operatorname{Ren}^{28}$ realizaram a determinação de $D$-chiro-inositol (25), Figura 11, um potente mediador do metabolismo de insulina presente no trigo Fagopyrum tataricum L. Gaench. Foi utilizada uma coluna de carboidrato ES, gradiente de acetonitrila em água, temperatura do drift tube de $95^{\circ} \mathrm{C}$ e fluxo do gás nebulizador de 2,2 L/min. O método desenvolvido por HPLC-ELSD foi sensível para a determinação de $D$-chiro-inositol com um limite de detecção de 100 $\mathrm{ng} / \mathrm{mL}$. Li e colaboradore ${ }^{29}$ realizaram a determinação quantitativa e qualitativa de glicose, frutose e sacarose presentes em bebidas por HPLC-ELSD. Para o ELSD operando com a temperatura do drift tube em $95{ }^{\circ} \mathrm{C}$ e a pressão do gás nebulizador em 4,0 bar, os limites de detecção obtidos para a glicose, frutose e sacarose foram de 93 , 126 e $90 \mu \mathrm{g} / \mathrm{mL}$, respectivamente.

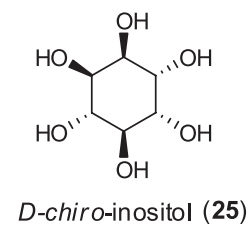

Figura 11. Estrutura do D-chiro-inositol $(25)^{28}$

Guenu e colaboradores ${ }^{30}$ descreveram a separação de maltodextrinas provenientes de plantas medicinais e de maltodextrinas comerciais. Foram desenvolvidos dois métodos de análise onde em um deles foi utilizada uma coluna $\mathrm{C}_{18}$ com os eluentes metanol e água e no outro, uma coluna amino-polimérica com acetonitrila e água como eluentes. Para o ELSD a temperatura do drift tube foi de $50{ }^{\circ} \mathrm{C}$ e a pressão do gás nebulizador foi de 3,5 bar. Os métodos associados ao ELSD permitiram uma excelente detecção de 12 compostos em 25 min de análise, além da determinação quantitativa de cada dextrina individualmente. Lehtonen e Hurme ${ }^{31}$ realizaram a determinação de mono e oligossacarídeos presentes em cerveja. Os autores utilizaram uma coluna polimérica, um gradiente de metanol em água, o ELSD operou com a temperatura do drift tube em $90{ }^{\circ} \mathrm{C}$ e a pressão do gás nebulizador em 1,5 bar. Os açúcares de baixo peso molecular (frutose, glicose, maltose e maltotriose) tiveram um limite de detecção na faixa de $5 \mathrm{mg} / \mathrm{L}$ e os açúcares de maior peso molecular (maltotetraose, maltopentaose, malto-hexaose e malto-heptaose) tiveram um limite de detecção na faixa de $10 \mathrm{mg} / \mathrm{L}$.

Yin e colaboradores ${ }^{32}$ utilizaram HPLC-ELSD para a determinação e purificação de estaquiose, sacarose e rafinose presentes em alcachofra chinesa (Stachys sieboldii Miq.). Foi empregada uma coluna de $\mathrm{NH}_{2}$, fase móvel de metanol, acetonitrila e água; para o ELSD o fluxo do gás nebulizador foi de $4,0 \mathrm{~mL} / \mathrm{min}$ e a temperatura do drift tube foi de $40^{\circ} \mathrm{C}$. O método mostrou ser simples, apropriado e confiável, apresentando boa linearidade, precisão e exatidão. Os limites de detecção para estaquiose, sacarose e rafinose foram de 0,10 ; 0,04 e $0,06 \mu \mathrm{g} / \mathrm{mL}$, respectivamente, e os limites de quantificação para estaquiose, sacarose e rafinose foram de 0,$25 ; 0,10$ e $0,15 \mu \mathrm{g} / \mathrm{mL}$, respectivamente, mostrando que o ELSD foi sensível para a análise destes carboidratos.

\section{Glicosídeos}

Podem ser encontradas na literatura diversas aplicações de ELSD para análise de glicosídeos presentes em matrizes vegetais ${ }^{33-39}$ como, por exemplo, Zhang e colaboradores, ${ }^{36}$ que realizaram a determinação de isoflavonoides glicosilados presentes em Astragalus membranaceus, e Li e colaboradores, ${ }^{37}$ que realizaram a análise de oito glicosídeos obtidos de Impatientis semen por HPLC-ELSD. No estudo realizado por Li e colaboradores, ${ }^{37}$ foram obtidos melhores resultados com o uso do ELSD com um fluxo de nitrogênio em 2,7
$\mathrm{L} /$ min e a temperatura do drift tube de $98^{\circ} \mathrm{C}$. O método foi preciso, obtendo-se boa repetibilidade das análises com um baixo limite de detecção na faixa de 11 a $29 \mu \mathrm{g} / \mathrm{mL}$ e limite de quantificação de 37 a $60 \mu \mathrm{g} / \mathrm{mL}$ dos hosenlosídeos A, B, C, F, G, K, L e M.

Cicek e colaboradores ${ }^{38}$ realizaram a análise quantitativa de 17 glicosídeos cicloartanos e da aglicona do cimigenol (26) presentes em Cohosh preto por HPLC-ELSD. Foi utilizada uma coluna de fase reversa $\mathrm{C}_{18}$, um gradiente de acetonitrila, metanol e água, temperatura do drift tube de $50{ }^{\circ} \mathrm{C}$ e um fluxo de gás nebulizador de $3,5 \mathrm{~L} / \mathrm{min}$. $\mathrm{O}$ método desenvolvido foi validado para precisão, repetibilidade e sensibilidade, pois todos os compostos puderam ser detectados e quantificados em uma faixa de 4 a 13,2 $\mu \mathrm{g} / \mathrm{mL}$. Foi ainda possível o isolamento de um novo composto natural, o 24-O-acetil-hidroshengmanol-3-O- $\alpha$-L: -arabinopiranosídeo (27), Figura 12.
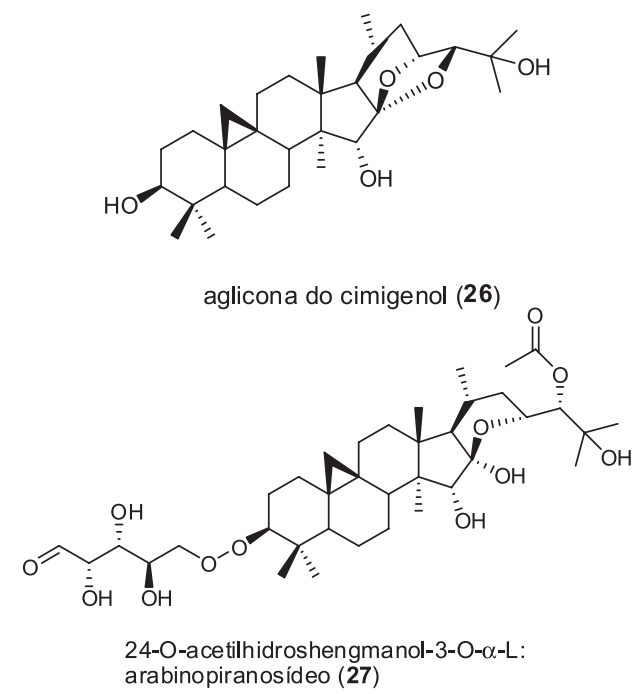

Figura 12. Estruturas da aglicona do cimigenol (26) e do 24-O-acetil-hidro-shengmanol-3-O- $\alpha$-L: -arabinopiranosídeo $(27)^{38}$

Lin e colaboradores ${ }^{39}$ utilizaram HPLC-ELSD para a análise de 10 glicosídeos presentes em Paris formosana Hayata. Foi usado um detector de UV em comparação com o detector de ELSD, que operaram nas mesmas condições cromatográficas com coluna $\mathrm{C}_{18}$, um gradiente de acetonitrila e água, temperatura do drift tube de $90{ }^{\circ} \mathrm{C}$ e um fluxo de gás nebulizador de 2,8 L/min. Os limites de detecção e de quantificação para o ELSD foram na faixa de 0,01 a 0,27 e 0,04 a $0,9 \mu \mathrm{g} / \mathrm{mL}$, respectivamente. Estes limites foram melhores do que os apresentados para o detector de UV.

\section{Alcaloides}

Regalado e colaboradores ${ }^{40}$ utilizaram cromatografia de fase reversa combinando HPLC com os detectores de UV e ELSD para a separação e purificação de alcaloides polares presentes na esponja marinha Niphates digitales. Os alcaloides esteroidais presentes em Veratrum nigrum (L.) são ao mesmo tempo tóxicos e apresentam atividade antifúngica e contra hipertensão. Cong e colaboradores ${ }^{41}$ realizaram um estudo do controle de qualidade e toxicológico dos alcaloides desta planta utilizando HPLC-ELSD. As condições ótimas no ELSD para a análise das substâncias foram de $70^{\circ} \mathrm{C}$ para a temperatura do drift tube e 50 psi para a pressão do gás nebulizador. $\mathrm{O}$ método validado mostrou ser reprodutível, preciso e sensível para a quantificação dos alcaloides. O limite de detecção obtido foi menor que $0,28 \mu \mathrm{g} / \mathrm{mL}$ e o DPR menor que $5 \%$ na avaliação da precisão interdia e intradia.

Yao e colaboradores ${ }^{42}$ realizaram a separação e purificação 
de diferentes componentes químicos da planta medicinal chinesa Adenophora tetraphlla. As condições usadas para o ELSD foram de $110^{\circ} \mathrm{C}$ para a temperatura do drift tube e $1,5 \mathrm{~L} / \mathrm{min}$ de fluxo de gás nebulizador. Obteve-se o isolamento de 9 compostos conhecidos e 1 desconhecido. Tang e colaboradores ${ }^{43}$ usaram HSCC-ELSD para o isolamento e purificação de dois novos alcaloides bioativos (Figura 13) provenientes dos extratos de Aconitum coreanum. Realizaram a otimização dos parâmetros do ELSD em termos da temperatura do drift tube, da vazão do fluxo de gás nebulizador e da razão de separação do efluente. Foi estudada a influência destas variáveis na eficiência da separação. O melhor sinal de detecção das amostras foi observado quando os parâmetros do ELSD foram estabelecidos em $100{ }^{\circ} \mathrm{C}$ para a temperatura do drift tube, $3,0 \mathrm{~L} / \mathrm{min}$ de fluxo de gás nebulizador e a razão de separação split de 3:1 $(3=$ coletor e 1 = ELSD), obtendo-se uma separação eficiente com $95 \%$ de pureza dos compostos isolados.

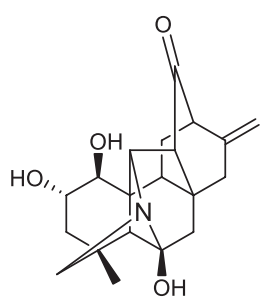

(28)

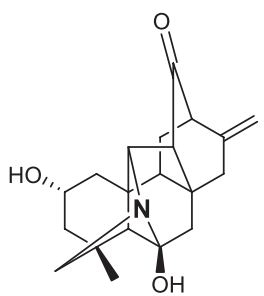

(29)
Figura 13. Estruturas dos alcaloides bioativos $(28 \text { e 29 })^{43}$

\section{Esteroides}

Os esteroides podem ser encontrados em plantas, fungos e animais e sua determinação pode ser feita utilizando um detector de ELSD. Wang e colaboradores ${ }^{44}$ realizaram a determinação das fumonisinas $\mathrm{B}_{1}(\mathbf{3 0}), \mathrm{B}_{2}(\mathbf{3 1}), \mathrm{B}_{3}(\mathbf{3 2})$ e $\mathrm{B}_{4}(\mathbf{3 3})$, micotoxinas produzidas pelo fungo Fusarium verticillioides, presentes em amostras de cereais por HPLC-ELSD. A análise foi realizada com coluna $\mathrm{C}_{18}$, gradiente de acetonitrila e água contendo ácido trifluoroacético em cada um dos solventes, e para o ELSD a temperatura do drift tube foi de $40{ }^{\circ} \mathrm{C} \mathrm{e}$ $2,0 \mathrm{~L} / \mathrm{min}$ de fluxo de gás nebulizador. $\mathrm{O}$ método desenvolvido foi sensível, exato e preciso apresentando um limite de detecção de 3 $\mathrm{ng} / \mu \mathrm{L}$ e sendo capaz de identificar as amostras (Figura 14) na faixa de 0,3 a $30 \mu \mathrm{g} / \mathrm{g}$.

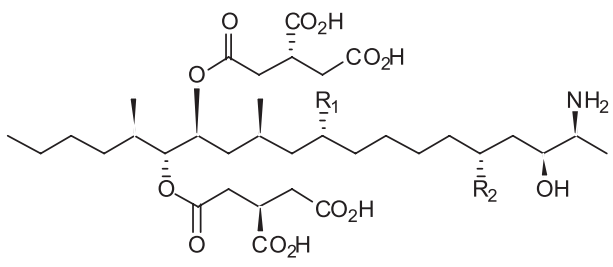

$\begin{array}{llll}\text { fumonisina } & \mathrm{R}_{1} & \mathrm{R}_{2} \\ \text { (30) } & \mathrm{B}_{1} & \mathrm{OH} & \mathrm{OH} \\ \text { (31) } & \mathrm{B}_{2} & \mathrm{H} & \mathrm{OH} \\ (32) & \mathrm{B}_{3} & \mathrm{OH} & \mathrm{H} \\ \text { (33) } & \mathrm{B}_{4} & \mathrm{H} & \mathrm{H}\end{array}$

Figura 14. Estruturas das fumonisinas (30-33 $)^{44}$

Graeve e Janssen ${ }^{45}$ desenvolveram um método de HPLC-ELSD para a separação e quantificação de esteroides presentes em diferentes espécies de zooplânctons marinhos. Foi utilizada uma coluna de sílica monolítica, solventes acetato de etila, isooctano, acetona, isopropanol e água, e o ELSD operou com temperatura do drift tube em $40{ }^{\circ} \mathrm{C}$ e pressão do gás nebulizador de 3,5 bar. O método desenvolvido mostrou ser robusto e sensível para a separação e quantificação de esteroides presentes em animais marinhos.

Os fitoesteróis, esteróis presentes em plantas, são usados para fins terapêuticos e de profilaxia no combate a doenças como arteriosclerose, câncer de próstata e câncer de cólon de útero. ${ }^{46}$ Diversos estudos foram realizados para a determinação de fitoesteróis por HPLC-ELSD ${ }^{46-53}$ como, por exemplo, Breinholder e colaboradores, ${ }^{47}$ que desenvolveram um método para a determinação de fitoesteroides presentes em diferentes sementes vegetais, e Zhao e colaboradores, ${ }^{48}$ que realizaram a determinação de oito esteroides presentes em Polyporus umbellatus.

Nair e colaboradores ${ }^{46}$ realizaram a validação de um método cromatográfico por HPLC-ELSD para a determinação de estigmasterol (34), $\beta$-sitosterol (35) e estigmastanol (36), Figura 15, encontrados em medicamentos fitoterápicos. Foi utilizada uma coluna $\mathrm{C}_{8}$, fase móvel de metanol e água, detector de UV operando na faixa de 200 a $400 \mathrm{~nm}$ e ELSD operando com temperatura do drift tube de $100{ }^{\circ} \mathrm{C}$ e um fluxo de gás nebulizador de $0,7 \mathrm{~L} / \mathrm{min}$. O detector de ELSD foi mais sensível que o detector de UV. O método de HPLC-ELSD desenvolvido mostrou ser rápido, preciso e exato, apresentando limites de detecção e de quantificação para o detector de ELSD de 2 e $5 \mu \mathrm{g} / \mathrm{mL}$, respectivamente. Estes limites foram melhores do que os obtidos com o detector de UV, que apresentou um limite de detecção de $5 \mu \mathrm{g} / \mathrm{mL}$ e limite de quantificação de $7 \mu \mathrm{g} / \mathrm{mL}$.

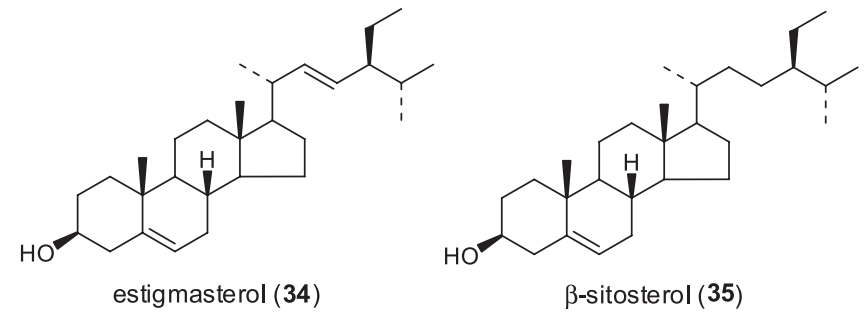<smiles>CC[C@H](CCC(C)C1CCC2[C@@H]3CCC4C[C@@H](O)CC[C@]4(C)C3CC[C@]12C)C(C)C</smiles>

Figura 15. Estrutura do estigmaesterol (34), $\beta$-sitosterol (35) e estigmastanol $(36)^{45}$

Yan e colaboradores ${ }^{49}$ desenvolveram um método de HPLC-DADELSD para a determinação de três esteroides, ácido cólico (37), ácido ursodesoxicólico (38) e ácido hiodesoxicólico (39) presentes em Qingkailing, uma formulação composta por oito extratos de plantas medicinais (Figura 16). Foi utilizada uma coluna $\mathrm{C}_{18}$ e gradiente de metanol, acetonitrila e água. Para o ELSD, as amostras foram analisadas com temperatura do drift tube em 90, 100, 110, 115 e 120 ${ }^{\circ} \mathrm{C}$ e fluxo de gás nebulizador em 1,$0 ; 1,5 ; 2,0 ; 2,5$ e 3,0. Melhores resultados foram obtidos para a temperatura do drift tube em $110^{\circ} \mathrm{C}$ e fluxo de gás nebulizador em 1,5 L/min, sendo que os limites de detecção para os ácidos cólico, ursodesoxicólico e hiodesoxicólico foram de 50,40 e $50 \mathrm{ng} / \mathrm{mL}$, respectivamente. 


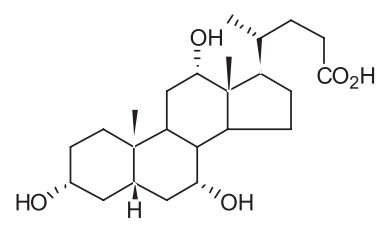
ácido cólico (37)<smiles>C[C@@H](CCC(=O)O)C1CCC2C3C[C@H](O)C4C[C@H](O)CCC4(C)C3CCC21C</smiles>

ácido hiodesoxicólico (39)

Figura 16. Estrutura do ácido cólico (37), ácido ursodesoxicólico (38) e ácido hiodesoxicólico $(\mathbf{3 9})^{46}$

\section{Flavonoides}

Lue e colaboradore ${ }^{54}$ desenvolveram um método de HPLC-ELSD para a quantificação de flavonoides hidrofílicos e ácidos graxos hidrofóbicos de cadeia longa em reações enzimáticas, na presença de diferentes líquidos iônicos à temperatura ambiente (RTIL). A redução de flavonoides ou o aumento de ésteres de flavonoides foram utilizados para o acompanhamento quantitativo da evolução da reação enzimática. Foram usadas colunas $\mathrm{C}_{8}, \mathrm{C}_{12} \mathrm{e}_{18}$; solventes de metanol, acetonitrila e água acidificada com ácido acético, acetato de amônio, ácido trifluoracético e trietilamina; detector de UV operando na faixa de 210 a $600 \mathrm{~nm}$ e ELSD com temperatura do drift tube em $90{ }^{\circ} \mathrm{C}$ e fluxo de gás nebulizador de 1,2 L/min. Melhores resultados foram alcançados com o uso do ELSD, coluna $\mathrm{C}_{8}$ e gradiente de metanol e solução tampão de trietilamina. O detector por espalhamento de luz foi escolhido devido a sua capacidade em detectar tanto os flavonoides quanto os ácidos graxos de interesse. Dentre os tampões utilizados, a solução de trietilamina apresentou ótimos resultados nas detecções por ELSD por ter uma boa solubilidade nos solventes orgânicos e ser volátil nas condições utilizadas para o ELSD. O método desenvolvido mostrou uma clara separação de todos os componentes da mistura, bem como uma boa linha de base e formato dos picos. Foi observada uma boa correlação linear entre a resposta do ELSD e a concentração de RTIL em 10 mg/mL.

Yu e colaboradore ${ }^{55}$ realizaram a determinação de 20 flavonoides presentes na planta medicinal Huang-qi por HPLC-DAD-ELSD. Foi utilizada coluna $\mathrm{C}_{18}$, gradiente de acetonitrila em água, temperatura do drift tube de $105{ }^{\circ} \mathrm{C}$ e fluxo de gás nebulizador de $2,7 \mathrm{~L} / \mathrm{min}$. Foram obtidos limites de detecção na faixa de 2,6 a $10 \mathrm{ng} / \mathrm{mL}$ e de quantificação na faixa de 11 a $30 \mathrm{ng} / \mathrm{mL}$. Li e Fitzloff ${ }^{56}$ também $^{-}$ utilizaram HPLC-ELSD para a determinação dos flavonoides quercetina (40), kaempferol (41) e isoramnetina (42) presentes em Ginkgo biloba. As amostras foram analisadas em coluna $\mathrm{C}_{18}$, gradiente de metanol em água e condições do ELSD otimizadas em $61{ }^{\circ} \mathrm{C}$ para a temperatura do drift tube e pressão do gás nebulizador em 2,9 bar. O método desenvolvido foi sensível, rápido e reprodutível, onde os flavonoides (Figura 17) apresentaram um limite de detecção na faixa de 20 a $35 \mathrm{ng} / \mathrm{mL}$.

Chen e colaboradores ${ }^{57}$ realizaram a determinação dos flavonoides rutina (43), lonicerina (44) e luteonina-7-O-glucosídeo (45) presentes em Flos lonicerae por HPLC-DAD-ELSD. Foi utilizada uma coluna $\mathrm{C}_{18}$, solventes acetonitrila e água com $0,5 \%$ de ácido acético, UV na faixa de $360 \mathrm{~nm}$ e ELSD operando com temperatura do drift tube<smiles>[R]c1cc(-c2oc3cc(O)cc(O)c3c(=O)c2O)ccc1O</smiles>

$\mathrm{R}$
(40) quercetina
$\mathrm{OH}$
(41) kaempferol
$\mathrm{H}$
(42) isoramnetina
$\mathrm{OMe}$

Figura 17. Estrutura da quercetina (40), kaempferol (41) e isoramnetina $(\mathbf{4 2})^{56}$

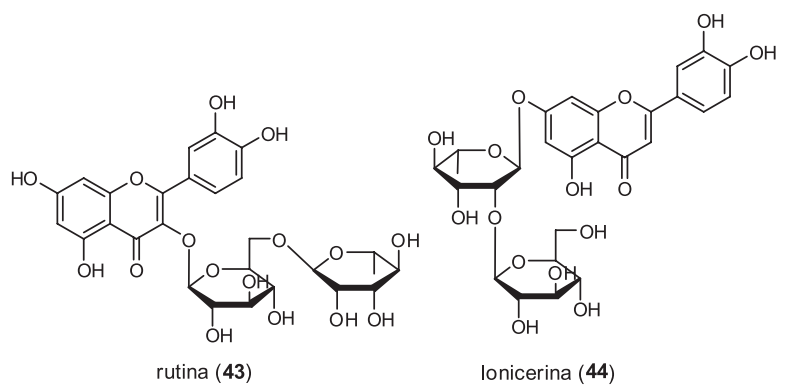

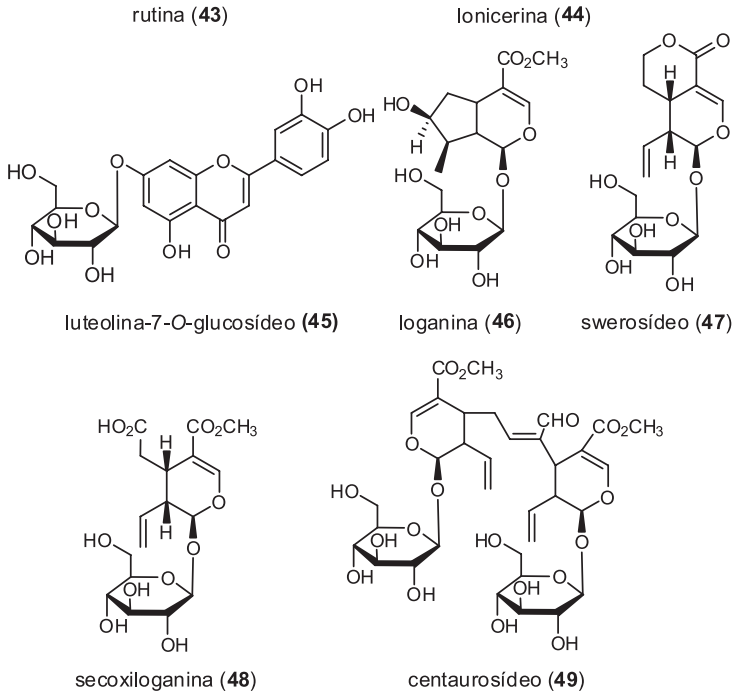

Figura 18. Estrutura da rutina (43), lonicerina (44), luteonina-7-O-glucosídeo (45) e dos iridoides $(46-49)^{57}$

em $110^{\circ} \mathrm{C}$ e fluxo do gás nebulizador de $3,0 \mathrm{~L} / \mathrm{min}$. Os flavonoides (Figura 18) apresentaram limite de detecção na faixa de 0,04 a $0,05 \mu \mathrm{g} / \mathrm{mL}$ e limite de quantificação na faixa de 0,15 a $0,17 \mu \mathrm{g} / \mathrm{mL}$.

\section{Peptídeos}

No estudo de peptídeos a escolha pelo método de ELSD é o mais indicado, pois é um método de análise direta que não requer derivatização prévia das amostras. Por exemplo, Adoubel e colaboradores ${ }^{58}$ realizaram a separação de peptídeos utilizando HPLC-ELSD com cromatografia de fase reversa por pareamento iônico, com o ELSD operando com temperatura do drift tube em $50{ }^{\circ} \mathrm{C}$ e pressão do gás nebulizador de 2,2 bar. Bongers e Chen ${ }^{59}$ utilizaram HPLC-ELSD em conjunto com detector de UV para o mapeamento de peptídeos de proteínas. Foi empregada coluna $\mathrm{C}_{18}$, gradiente de acetonitrila, água e ácido trifluoracético, temperatura do drift tube em $40{ }^{\circ} \mathrm{C}$ e pressão do gás nebulizador de 2,1 bar. McClintic e colaboradores ${ }^{60}$ realizaram a determinação de piperazinas (Figura 19) por HPLC-ELSD. 
Utilizaram coluna de cianopropil, solventes acetonitrila, água e ácido trifluoracético e condições do ELSD otimizadas em $75^{\circ} \mathrm{C}$ para a temperatura do drift tube e fluxo do gás nebulizador em 1,75 L/min. O método desenvolvido mostrou níveis aceitáveis de linearidade, precisão, seletividade e limite de detecção na faixa de $100 \mathrm{ng} / \mathrm{mL}$.
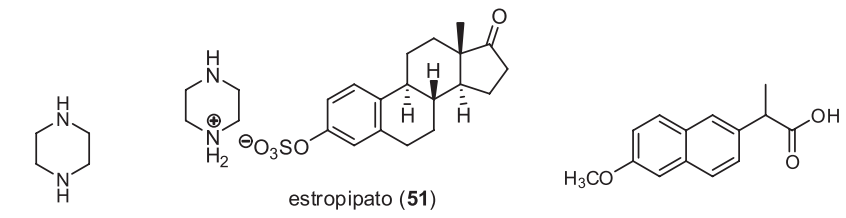

piperazina (50) (sal de piperazina de sulfato de estrona) naproxeno (52)

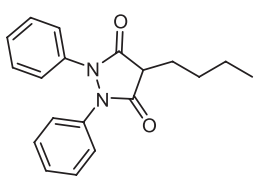

fenilbutazona $(53)$

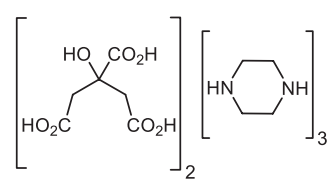

citrato de piperazina (54)
Figura 19. Estruturas das piperazinas (50-54) $)^{60}$

Peterson e colaboradores ${ }^{61}$ escolheram a detecção por espalhamento de luz evaporativo para a análise de 18 aminoácidos obtidos do hormônio PTH da paratireoide humana (um polipeptídeo sintético). Utilizaram HPLC-ELSD com coluna de troca catiônica, solventes de água, ácido trifluoracético e acetato de amônio, temperatura do drift tube de $70{ }^{\circ} \mathrm{C}$ e fluxo de gás nebulizador de $1,5 \mathrm{~L} / \mathrm{min}$. O método desenvolvido foi validado em termos de precisão, exatidão e linearidade, apresentando um limite de detecção na faixa de 25 a $7500 \mathrm{nmol} / \mathrm{mL}$.

Peptídeos originários de micro-organismos também puderam ser eficientemente analisados por ELSD. Por exemplo, $\mathrm{Xu}$ e $\mathrm{Du}^{62}$ realizaram a análise de toxinas produzidas por Alternaria alternata lycopersici por HPLC-ELSD, obtendo um limite de detecção de 6 ng/ $\mu$ L. Sarri e colaboradores ${ }^{63}$ desenvolveram um método de HPLCELSD para a análise das principais bacitracinas, Bc-A (55), Bc-B (56), Bc-B ${ }_{2}$ (57), Bc-B ${ }_{3}$ (58) e Bc-F (59), polipeptídeos cíclicos produzidos por linhagens de Bacillus licheniformis e Bacillus subtilis. Foi utilizada uma coluna $\mathrm{C}_{8}$, solventes de acetonitrila e água contendo ácido trifluoracético e condições do ELSD otimizadas em $50{ }^{\circ} \mathrm{C}$ para a temperatura do drift tube e 3,5 bar para a pressão do gás nebulizador. O método desenvolvido foi validado em termos de precisão, exatidão e limites de detecção e quantificação. $\mathrm{O}$ uso de ELSD associado ao HPLC para a análise das bacitracinas (Figura 20) mostrou ser vantajoso por permitir a análise das substâncias sem a etapa de derivatização, além de apresentar um curto tempo

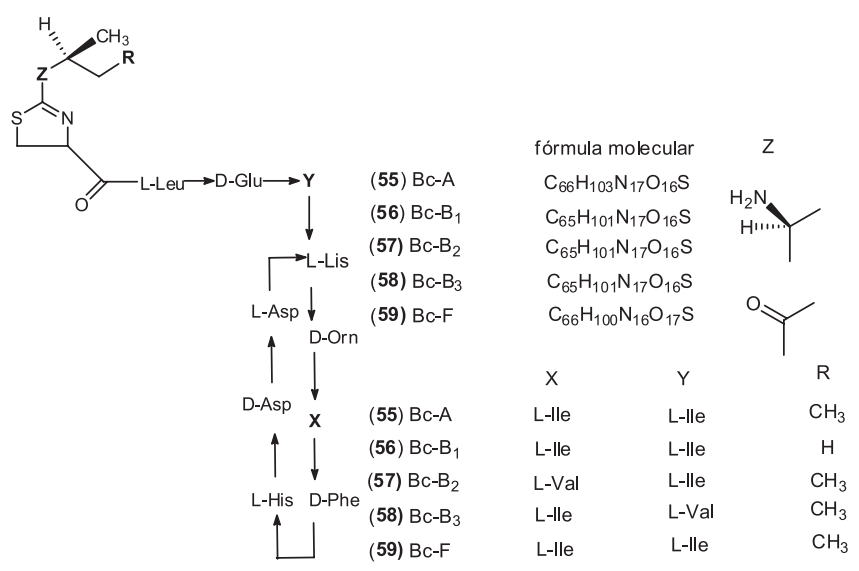

Figura 20. Estruturas das bacitracinas (55-59) ${ }^{63}$ de análise com tr de no máximo 16 min e um limite de detecção na faixa de 1,0 a $1,6 \mu \mathrm{g} / \mathrm{mL}$.

O fungo Beauveria felina produz destruxinas em meio de cultura, ciclodepsipeptídeos entomopatogênicos que são utilizados como controle biológico de insetos pragas em diferentes culturas agrícolas. Foi desenvolvido um método para análise das destruxinas (Figura 21) de B. felina por HPLC-DAD-ELSD-MS. ${ }^{64}$

$$
\begin{aligned}
& \mathrm{R}_{1}=\mathrm{CH}(\mathrm{Me}) \mathrm{CH}_{2} \mathrm{Me} \text { ou } \mathrm{CH}_{2} \mathrm{Ph}_{\text {ou } \mathrm{CHMe}_{2}} \\
& \mathrm{R}_{2}=\mathrm{Me} \text { ou H } \\
& \mathrm{R}_{3}=\mathrm{Me} \text { ou H } \\
& \mathrm{R}_{4}=\mathrm{Me}
\end{aligned}
$$

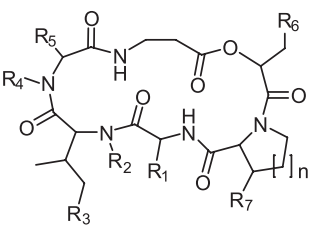

Figura 21. Estruturas das destruxinas $(60)^{64}$

A nova abordagem fez uso de limpeza prévia das amostras por extração em fase sólida. Para as análises foi utilizada uma coluna $\mathrm{C}_{18}$ e um gradiente de metanol, acetonitrila e água com $0,1 \%$ de ácido fórmico em cada um dos solventes. A faixa de detecção no UV foi de 205 a $254 \mathrm{~nm}$. O ELSD operou com temperatura do drift tube de $75^{\circ} \mathrm{C}$ e a pressão do gás nebulizador de $50 \mathrm{psi}$. Foram observadas 20 destruxinas conhecidas e 6 ciclodepsipetídeos ainda desconhecidos. Detecções simultâneas usando UV (arranjo de diodos), ELSD e MS indicaram respostas praticamente idênticas de todos os detectores na análise das destruxinas. O método desenvolvido foi validado em termos de seletividade, precisão e estabilidade. Considerando-se a eficácia e menor custo do ELSD como detector para destruxinas, o método mostrou ser de grande valia para controle de qualidade nas análises de destruxinas produzidas por linhagens de fungos utilizados em controle biológico.

\section{Policetídeos, iridoides e cumarinas}

O número de trabalhos publicados descrevendo o uso de ELSD para a análise de policetídeos, ${ }^{65-67}$ iridoides ${ }^{57,68,69}$ e cumarinas ${ }^{70}$ é relativamente pequeno. Policetídeos bioativos obtidos da esponja marinha Plakortis zyggompha foram isolados por Berrue e colaboradores, ${ }^{65}$ utilizando detecção por HPLC-DAD-ELSD. Pistorino e Pfeifer ${ }^{67}$ utilizaram um detector por espalhamento de luz evaporativo para analisar o 6-deoxieritronolídeo B (61), um precursor da eritromicina (62) que não possui grupos cromóforos (Figura 22).

O ELSD foi comparado com o espectrômetro de massas (MS) e com o detector por aerossol carregado (CAD). Foi utilizada

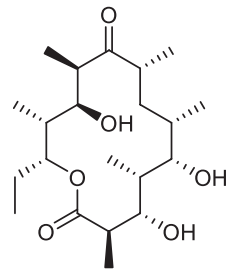

6-deoxieritronolídeo B (61)

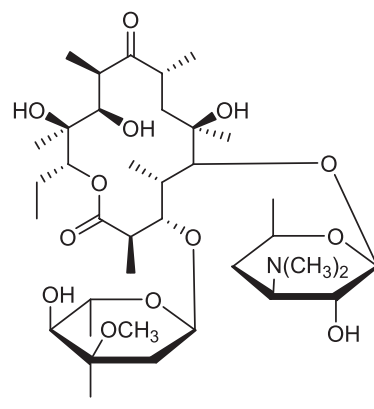

eritromicina $(62)$
Figura 22. Estrutura do 6-deoxieritronolídeo B (61) e da eritromicina $(62)^{67}$ 
acetonitrila como solvente e o ELSD operou com temperatura do drift tube em $55^{\circ} \mathrm{C}$ e pressão do gás nebulizador em 3,0 bar. $\mathrm{O}$ detector por espectrometria de massas foi a melhor opção para a análise de baixas concentrações de 6-deoxieritronolídeo B, apresentando o melhor limite de detecção. Comparativamente, tanto o CAD quanto o ELSD apresentaram melhor precisão e exatidão, porém o ELSD apresentou uma melhor precisão a um nível de $3 \%$ a mais que os outros dois detectores.

A planta medicinal Flos lonicerae é utilizada na medicina chinesa para o tratamento de febre aguda, dor de cabeça, infecção respiratória, epidemias, dentre outros males. Os metabólitos secundários presentes nesta planta que são responsáveis pela sua ação curativa são os iridoides, flavonoides, saponinas e ácidos fenólicos..$^{57}$ Os iridoides obtidos de Flos lonicerae (estruturas de 46 a 48; 63 e 64 - Figuras 18 e 23) foram determinados primeiramente por Li e colaboradores, ${ }^{69}$ utilizando um sistema HPLC-ELSD.

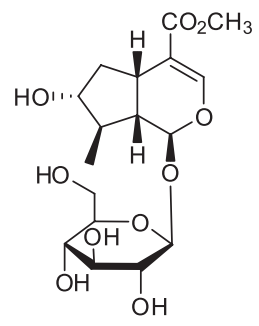

7-epi-loganina $(63)$

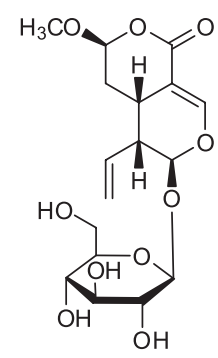

7-epi-vogelosídeo (64)
Figura 23. Estruturas dos iridoides 7-epi-loganina (63) e 7-epi-vogelosídeo $(\mathbf{6 4})^{69}$

A melhor condição para a separação e detecção dos 5 iridoides foi obtida utilizando-se coluna $\mathrm{C}_{18}$, fase móvel de metanol e água com $0,5 \%$ de ácido acético em cada um dos solventes e para o ELSD temperatura do drift tube em $90^{\circ} \mathrm{C}$ e fluxo do gás nebulizador de 2,6 $\mathrm{L} / \mathrm{min}$. O método desenvolvido apresentou boa reprodutibilidade para a quantificação dos iridoides, apresentando um limite de detecção menor que $35,1 \mu \mathrm{g} / \mathrm{mL}$ e um limite de quantificação abaixo de $140,1 \mu \mathrm{g} / \mathrm{mL}$.

Chen e colaboradores ${ }^{56}$ também utilizaram HPLC-DAD-ELSD para a determinação de 4 iridoides presentes em Flos lonicerae (Figura 19). Empregaram coluna $\mathrm{C}_{18}$, solventes acetonitrila e água com $0,5 \%$ de ácido acético, UV na faixa de $240 \mathrm{~nm}$ e para o ELSD temperatura do drift tube em $110{ }^{\circ} \mathrm{C}$ e fluxo do gás nebulizador de 3,0 L/min. O método desenvolvido foi validado em termos de precisão, exatidão e estabilidade, apresentando limite de detecção na faixa de 0,13 a $0,17 \mu \mathrm{g} / \mathrm{mL}$ e limite de quantificação na faixa de 0,51 a $0,96 \mu \mathrm{g} / \mathrm{mL}$.

Sajewicz e colaboradores ${ }^{70}$ realizaram a análise de seis espécies de Salvia officinalis L. por HPLC-DAD-ELSD. Usaram cumarinas e outras substâncias como padrões fitoquímicos para a análise dos perfis cromatográficos das diferentes amostras de Salvia. As análises demonstraram que os cromatogramas obtidos por ELSD foram mais ricos em termos quantitativos e qualitativos do que os cromatogramas obtidos pelo detector de UV. O ELSD forneceu informações sobre a composição total das substâncias presentes nas amostras, enquanto que o DAD forneceu informações a respeito de substâncias específicas que absorvem no UV.

\section{CONCLUSÕES}

O uso do detector por espalhamento de luz evaporativo para análise de produtos naturais teve seu início no final dos anos 80, com a análise de compostos que não apresentavam absorção no ultravioleta. ${ }^{71}$ Os primeiros compostos a serem estudados foram carboidratos, ${ }^{23-30}$ sendo obtidos bons resultados com este detector. Assim, outras classes de compostos passaram a ser analisadas como, por exemplo, saponinas, ${ }^{8-15}$ glicosídeos ${ }^{31-39}$ e terpenos. ${ }^{16-22}$ Recentemente, classes adicionais de produtos naturais estão sendo estudadas e há ainda um número pequeno de trabalhos publicados utilizando ELSD para análise de policetídeos, ${ }^{65-67}$ iridoides $^{57,68,69}$ e cumarinas. $^{70}$

O ELSD é recomendado para substâncias que não são sensíveis a altas temperaturas e pode ser aplicado para análise de todas as classes de produtos naturais, como exemplificado acima. É compatível com eluição gradiente, onde a mudança na composição do solvente não interfere na linha de base. Pode ser utilizado qualquer tipo de solvente, independente da sua polaridade, desde que sejam voláteis na temperatura de evaporação escolhida e, também, pode ser aplicada uma ampla faixa de temperatura de evaporação. ${ }^{2}$

O ELSD é versátil, de fácil operação, não necessita de derivatização das amostras, independe de mudanças de temperatura, composição e variações no fluxo da fase móvel. Pode ser adotado como uma alternativa e, também, como um aliado ao detector de UV por ser barato, rápido e não necessitar de grupos cromóforos nas substâncias a serem analisadas. ${ }^{2}$ Mesmo com a grande superioridade da espectrometria de massas, o uso do ELSD vem crescendo significativamente, devido as suas vantagens discutidas anteriormente, mostrando que é uma valiosa técnica de detecção para análise de produtos naturais.

\section{REFERÊNCIAS}

1. Megoulas, N. C.; Koupparis, M. A.; Crit. Rev. Anal. Chem. 2005, 35, 301 .

2. Ganzera, M.; Stuppner, H.; Curr. Pharm. Anal. 2005, 1, 135.

3. Christie, W. W.; Lipid Technol. 1993, 5, 68.

4. Christie, W. W.; Lipid Technol. 1989, 1, 23.

5. Nicolau, A.; Mariath, R. M.; Samios, D.; Mater. Sci. Eng., C 2009, 29, 452

6. Cobb, Z.; Shaw, P. N.; Lloyd, L. L.; Wrench, N.; Barret, D. A.; J. Microcolumn Sep. 2001, 13, 169.

7. Chopra, S.; Vanderheyden, G.; Hoogmartens, J.; Schepdael, A. V.; Adams, E.; J. Pharm. Biomed. Anal. 2010, 53, 151.

8. He, K.; Pauli, G. F.; Zheng, B.; Wang, H. K.; Bai, N. S.; Peng, T. S.; Roller, M.; Zheng, Q. Y.; J. Chromatogr., A 2006, 1112, 241.

9. Kwon, S. W.; Han, S. B.; Park, I. H.; Kim, J. M.; Park, M. K.; Park, J. H.; J. Chromatogr., A 2001, 921, 335.

10. Li, W.; Fitzloff, J. F.; J. Liq. Chromatogr. Relat. Technol. 2002, $25,17$.

11. Rupasinghe, H. P. V.; Jackson, C. J. C.; Poysa, V.; Di Berardo, C.; Bewley, J. D.; Jenkinson, J.; J. Agric. Food Chem. 2003, 51, 5888.

12. Cao, X. I.; Tian, Y.; Zhang, T. Y.; Liu, Q. H.; Jia, L. J.; Ito, Y.; J. Liq. Chromatogr. Relat. Technol. 2003, 26, 1579.

13. Wang, H.; Gao, J.; Zhu, D.; Yu, B.; J. Pharm. Biomed. Anal. 2007, 43, 1552.

14. Wang, H. L.; Yao, W. F.; Zhu, D. N.; Hu, Y. Z.; Chin. J. Nat. Med. 2010, 8,343 .

15. Bhandari, P.; Kumar, N.; Singh, B.; Singh, V.; Kaur, I.; J. Sep. Sci. 2009, 32, 2812.

16. Man, S.; Gao, W.; Zhang, Y.; Wang, J.; Zhao, W.; Huang, L.; Liu, C.; J. Chromatogr., B: Anal. Technol. Biomed. Life Sci. 2010, 878, 2943.

17. Avula, B.; Wang, Y. H.; Smillie, T. J.; Fu, X.; Li, X. C.; Mabusela, W.; Syce, J.; Johnson, Q.; Folk, W.; Khan, I. A.; J. Pharm. Biomed. Anal. 2010, 52, 173 .

18. Kong, L.; Li, X.; Zou, H.; Wang, H.; Mao, X.; Zhang, Q.; Ni, J.; J. Chromatogr., A 2001, 936, 111.

19. Christen, P.; Veuthey, J. L.; Curr. Med. Chem. 2001, 8, 1827. 
20. Lapkin, A. A.; Walker, A.; Sullivan, N.; Khambay, B.; Mlambo, B.; Chemat, S.; J. Pharm. Biomed. Anal. 2009, 49, 908.

21. Devkota, A.; Dall'Acqua, S.; Comai, S.; Innocenti, G.; Jha, P. K.; Biochem. Syst. Ecol. 2010, 38, 12.

22. van Beek, T. A.; J. Chromatogr., A 2002, 967, 21.

23. Dubber, M. J.; Kanfer, I.; J. Pharm. Biomed. Anal. 2006, 41, 135.

24. Kaur, P.; Chaudhry, A.; Singh, B.; Gopichand; J. Pharm. Biomed. Anal. 2009, 50, 1060.

25. Biesiekierski, J. R.; Rosella, O.; Rose, R.; Liels, K.; Barrett, J. S.; Shepherd, S. J.; Gibson, P. R.; Muir, J. G.; J. Hum. Nutr. Dietetics 2011, 24, 154.

26. Filson, P. B.; Dawson-Andoh, B. E.; Bioresour. Technol. 2009, 100, 6661.

27. Wang, S.; Yang, F. Q.; Feng, K.; Li, D. Q.; Zhao, J.; Li, S. P.; J. Sep. Sci. 2009, 32, 4069.

28. Yang, N.; Ren, G. X.; J. Agric. Food Chem. 2008, 56, 757.

29. Li, J.; Chen, M. L.; Zhu, Y.; J. Chromatogr., A 2007, 1155, 50.

30. Guenu, S.; Seigneuret, J. M.; Dreux, M.; J. Liq. Chromatogr. Relat. Technol. 2000, 23, 2883.

31. Lehtonen, P.; Hurme, R.; J. Inst. Brew. 1994, 100, 343.

32. Yin, J. F.; Yang, G. L.; Wang, S. M.; Chen, Y.; Talanta 2006, 70, 208.

33. Mukhopadhyay, S.; Luthria, D. L.; Robbins, R. J.; J. Sci. Food Agric. 2006, 86, 156

34. Yang, D. J.; Lu, T. J.; Hwang, L. S.; J. Food Drug Anal. 2003, 11, 271.

35. Ganzera, M.; Bedir, E.; Khan, I. A.; Chromatographia 2000, 52, 301.

36. Zhang, L. J.; Liu, H. K.; Hsiao, P. C.; Kuo, L. M. Y.; Lee, I. J.; Wu, T. S.; Chiou, W. F.; Kuo, Y. H.; J. Agric. Food Chem. 2011, 59, 1131.

37. Li, H. J.; Yu, J. J.; Li, P.; J. Pharm. Biomed. Anal. 2011, 54, 674.

38. Cicek, S. S.; Aberham, A.; Ganzera, M.; Anal. Bioanal. Chem. 2011, 400,2597

39. Lin, J. T.; Chang, Y. Z.; Lu, M. P.; Yang, D. J.; J. Agric. Food Chem. 2011, 59, 1587

40. Regalado, E. L.; Mendiola, J.; Laguna, A.; Nogueiras, C.; Thomas, O. P.; Nat. Prod. Commun. 2010, 5, 1187.

41. Cong, Y.; Zhou, Y. B.; Chen, J.; Zeng, Y.; M.; Wang, J. H.; J. Pharm. Biomed. Anal. 2008, 48, 573.

42. Yao, S.; Liu, R.; Huang, X.; Kong, L.; J. Chromatogr., A 2007, 1139, 254.

43. Tang, Q.; Liu, J.; Xue, J.; Ye, W.; Zhang, Z.; Yang, C.; J. Chromatogr., B: Anal. Technol. Biomed. Life Sci. 2008, 872, 181.

44. Wang, J.; Zhou, Y.; Wang, Q.; Food Chem. 2008, 107, 970.

45. Graeve, M.; Janssen, D.; J. Chromatogr., B: Anal. Technol. Biomed. Life Sci. 2009, 877, 1815
46. Nair, V. D. P.; Kanfer, I.; Hoogmartens, J.; J. Pharm. Biomed. Anal. 2006, $41,731$.

47. Breinholder, P.; Mosca, L.; Lindner, W.; J. Chromatogr., B: Anal. Technol. Biomed. Life Sci. 2002, 777, 67.

48. Zhao, Y. Y.; Cheng, X. L.; Zhang, Y. M.; Zhao, Y.; Lin, R. C.; Sun, W. J.; Biomed. Chromatogr. 2010, 24, 222.

49. Yan, S. K.; Luo, G. A.; Wang, Y. M.; Cheng, Y. Y.; J. Pharm. Biomed. Anal. 2006, 40, 889.

50. Oleszek, W.; Bialy, Z.; J. Chromatogr., A 2006, 1112, 78.

51. Tang, J.; Li, H. L.; Shen, Y. H.; Jin, H. Z.; Yan, S. K.; Liu, R. H.; Zhang, W. D.; Chromatographia 2008, 67,15.

52. Lin, J. T.; Liu, S. C.; Chen, S. L.; Chen, H. Y.; Yang, D. J.; J. Agric. Food Chem. 2006, 54, 9948.

53. Osada, K.; Ravandi, A.; Kuksis, A.; J. Am. Oil Chem. Soc. 1999, 76, 863.

54. Lue, B. M.; Guo, Z.; Xu, X. B.; J. Chromatogr., A 2008, 1198, 107.

55. Yu, Q. T.; Qi, L. W.; Li, P.; Yi, L.; Zhao, J.; Bi, Z. M.; J. Sep. Sci. 2007, 30, 1292

56. Li, W. K.; Fitzloff, J. F.; J. Pharm. Biomed. Anal. 2002, 30, 67.

57. Chen, C. Y.; Oi, L. W.; Li, H. J.; Li, P.; Yi, L.; Ma, H. L.; Tang, D.; J. Sep. Sci. 2007, 30, 3181.

58. Adoubel, A. A.; Guenu, S.; Elfakir, C.; Dreux, M.; J. Liq. Chromatogr. Relat. Technol. 2000, 23, 2433.

59. Bongers, J.; Chen, T. K.; J. Liq. Chromatogr. Relat. Technol. 2000, 23, 925.

60. McClintic, C.; Remick, D. M.; Peterson, J. A.; Risley, D. S.; J. Liq. Chromatogr. Relat. Technol. 2003, 26, 3093.

61. Peterson, J. A.; Lorenz, L. J.; Risley, D. S.; Sandmann, B. J.; J. Liq. Chromatogr. Relat. Technol. 1999, 22, 1009.

62. Xu, L.; Du, L.; J. Microbiol. Methods 2006, 64, 398

63. Sarri, A. K.; Megoulas, N. C.; Koupparis, M. A.; Anal. Chim. Acta 2006, 573, 250

64. Morais, R. P.; Lira, S. P.; Seleghim, M. H. R.; Berlinck, R. G. S.; J. Braz. Chem. Soc. 2010, 21, 2262.

65. Berrue, F.; Thomas, O. P.; Laville, R.; Prado, S.; Golebiowski, J.; Fernandez, R.; Amade, P.; Tetrahedron 2007, 63, 2328.

66. Pistorino, M.; Pfeifer, B. A.; Biotechnol. Prog. 2009, 25, 1364.

67. Pistorino, M.; Pfeifer, B. A.; Anal. Bioanal. Chem. 2008, 390, 1189.

68. Chen, J.; Song, Y.; Li, P.; J. Chromatogr., A 2007, 1157, 217.

69. Li, H. J.; Li, P.; Ye, W. C.; J. Chromatogr., A 2003, 1008, 167.

70. Sajewicz, M.; Staszek, D.; Wojtal, L.; Kowalska, T.; Hajnos, M. L.; Waksmundzka-Hajnos, M.; J. AOAC Int. 2011, 94, 71.

71. Bruns, A.; Waldhoff, H.; Winkle, W.; Chromatographia 1989, 27, 340. 